\title{
Thermal and Spectroscopic Analyses on the Molecular Interaction Between Eucalyptus Kraft Pulp Components and Offset Printing Inks
}

\author{
Ericka Figueiredo Alves $^{1 *}$, Rubens Chaves de Oliveira ${ }^{2}$, Luis Henrique Mendes da Silva ${ }^{3}$ \\ and Jorge Luiz Colodette ${ }^{4}$ \\ ${ }^{I}$ Department of Paper and Bioprocess Engineerin; SUNY-College of Environmental Science and Forestry; 413; \\ Walters Hal; 1 Forestry Drive, 13210; Syracuse - NY - USA. ${ }^{2,4}$ Laboratórios de Celulose e Papel; Departamento de \\ Engenharia Florestal; Universidade Federal de Viçosa, 36570-000; Viçosa - MG - Brasil. ${ }^{3}$ Departamento de \\ Química; Universidade Federal de Viçosa; 36570-000; Viçosa - MG - Brasil
}

\begin{abstract}
Thermal and infrared spectroscopic analyzes were carried out in order to study the kind of interaction between the anatomical components of the bleached eucalyptus kraft pulp with offset inks. A Bauer-McNett fiber classifier was used in order to obtain the anatomical components of the pulp, separately. The determinations of the enthalpy of the processes occurring in the samples of inks and pulp, as well as the enthalpy of these components interactions were obtained by Differential Scanning Calorimetry. In the interaction between pulp and offset ink, the reduced enthalpy values of the endothermic peak were interpreted as due to the released energy for adhesion of the ink pigment to the substratum. The low enthalpy value, 58 to 121 cal.g, ${ }^{-1}$ indicated that the settling of the ink occurs by physical interactions. The pulp fraction enriched with vessel elements caused a higher energy release during the adherence of the pigment into the pulp.
\end{abstract}

Key words: differential scanning calorimetry, thermogravimetry, kraft pulping, cellulose, interaction, and eucalyptus sp.

\section{INTRODUCTION}

The pulps proceeding from the tropical forest species (Ramos, 2000) may cause problems in the papermaking process, because of the structure of their chemical and anatomical components, a wellknown fact in the graphic and papermaking medium. Some problems such as the vessel picking might occur during the printing process. The vessel picking is related to a phenomenon in which some vessel elements found on the surface of the paper rather tend to be removed through the process of adhesion with the printing ink, thus creating some defective points on the printed surface (Ohsawa, 1988).

The vessel elements are shown under shapes forms that vary according the species and the widest and shortest shapes are the ones causing problems during the offset printing process of both coated and uncoated papers. These elements found on the

\footnotetext{
* Author for correspondence: efalves@ syr.edu
} 
surface are visibly noticed for presenting a higher shine, when exposed towards the light. In certain printed materials, one may observe that the printing faults are much more pronounced in some colors than in other ones (Colley et al., 1986). Some authors have mentioned that these faults may could be due to the differentiated interaction of the pulp components, fibers, and vessel elements with the printing inks.

One follow-up accomplished in the industry is to measure the dimensions of the vessel elements (length- $\mathrm{L}$ and width-D) and the percent rate of fibers and vessel elements. The companies' genetic improvement program has been searching for a high width/length relationship and low fiber/vessel rate, in order to minimize the printing problems of the eucalyptus papers. Another method used in reducing the picking is the increased refine degree of the pulp for papermaking (Heintze and Shallhorn, 1995).

In the graphic industry, the printing techniques require a careful control on the interaction of the ink components with the printing system and the paper. In the development of the printing inks It is necessary to take several factors into account such as the adhesion work among their components and the plate, blanket, dampening water and the paper. There is a scarce knowledge on those interactions, although several observations have shown their importance. One way to obtaining better quality in the printed paper is getting better adhesion between the ink and paper, by determining the thermodynamic parameters involved in the process. Thus, the reactions or the phase changing process with enthalpies depending on the temperature might be followed by DSC.

In this study, thermal and spectroscopy analyses were carried out in order to determine the interaction between the anatomical components of the bleached eucalyptus kraft pulp of with the offset printing inks.

\section{MATERIAL AND METHODS}

The industrial Kraft pulp of Eucalyptus spp was bleached by ECF technology, proceeding from the industrial unit Suzano Papel e Celulose - MucuriBA.

The offset inks were supplied by the company Lorigraf JF Tintas Especiais Ltda located in Juiz de Fora county, MG. For this experiment, the manufacturer prepared three europa-blue colored inks with similar chemical composition (Table 1) and three ranges: low Tack- 120 to 160 g.m.; medium Tack - 161 to 200 g.m. and high Tack 201 to 250 g.m.

Table 1 - Composition of the used offset inks.

\begin{tabular}{ll}
\hline Composite & Type \\
\hline Resins & phenolic, alkydic and hydrocarbonic \\
Vegetal oil & soybean, linseed, and alky-refined \\
Mineral oil & deodorized aliphatic \\
Pigment & organic \\
Others & modifiers, waxes, antioxidants, drier agents \\
\hline
\end{tabular}

\section{Pulp classification in Bauer-McNett}

In order to separate the anatomical elements found in the bleached pulp, the fiber classifier BauerMcNett provided with a system of sieves with 20 , 48, 100 and 200 mesh that was able to separate fiber samples into fractions or groups was used.

A pulp sample equivalent to $10 \mathrm{~g}$ o.d. (over dry) was weighed and quantitatively transferred at $4 \%$ consistence to a laboratory hydrapulper. After desagregation at 30,000 rpm, the water-suspended pulp was introduced into the highest tank of the classifier, from which it fed by gravity the four inferior classification tanks for a 15 min period. After classification, the fractions retained in those four qualifying sieves of the tanks were discharged into centrifuge until reaching a consistence around $40 \%$, in order to determine the fiber/vessel rate.

\section{The fiber/vessel rate of the pulp}

After classification of the pulp in Bauer-McNett, an amount of $10 \mathrm{~g}$ o. d. pulp from each fraction were randomly sampled for determination of the fiber/vessel rate. Each fraction was moistened for $24 \mathrm{~h}$ approximately; then, it was disintegrated at $30,000 \mathrm{rpm}$ in a laboratory hydrapulper at $25 \%$ consistency. Later, these pulp fractions were subjected to two successive dilutions. The first dilution resulted into $0.05 \%$ consistence and the 
second one into $0.0025 \%$. The dilutions were accomplished by agitation. An amount of $250 \mathrm{~mL}$ from each fractional sample were collected under constant homogenization, and the paper sheet was formed in a Tappi former. The hand sheet was dried at $105 \pm 3{ }^{\circ} \mathrm{C}$ for 20 minutes. After drying, four distinct areas of the sheet were sampled with transparent adhesive tape and allocated on microscope glass plate in order to be quantified in computerized microscopy system. Eight glass plates from each fractional sample were quantified, by counting of 1,500 fibers by plate and the respective amount of the vessel elements present in this quantification.

In order to standardizing the nomenclature of the fractions of the classified pulps used in the subsequent stages, these fractions were named in relation to the analysis of the fiber/vessel rate, therefore being classified into low, medium and high pulps for the fiber/vessel rate.

\section{Chemical and physical characteristics of the pulp}

The characterization of the pulp was carried out in triplicate, by evaluating the fibers count/grams (million), average length of the fibrous material $(\mathrm{mm})$, average diameter of the fibrous material $(\mathrm{mm})$, coarseness $(\mathrm{mg} / 100 \mathrm{~g})$, fines $(\%)$ of the pulp. The pulp suspensions were prepared in distilled water, at $0.001 \%$ consistency and dispersant (2.0\% pulp base) was added to them. The analysis was accomplished by using the image analyzer (GALAI CIS-100) with its respective software Wshape. For calculation of the percent fine occurrences, the dimensions equal or lower than $0.07 \mathrm{~mm}$ were considered. The air resistance $\left(\mathrm{s} / 100 \mathrm{~cm}^{3}\right.$ air) was carried out according to the norm TAPPI T536 om-96, whereas the carbohydrate analyses followed the norm TAPPI T249 cm-00 modified.

\section{Analyses by Differential Scanning Calorimetry (DSC) and Thermogravimetry (TGA)}

In these analyses, a hand sheet made in a laboratorial former according to Tappi T205 sp-95 was used.

For the determination of the thermodynamic parameters, three types of pulp samples (low, medium and high fiber/vessel rate) were taken, by using a perforator with a diameter around $6.4 \mathrm{~mm}$, resulting into $4.5 \pm 0.2 \mathrm{mg}$ weight for each sample. For inks with low, medium, and high tack, $9 \pm 0.2$ $\mathrm{mg}$ were used. Finally, for determining the thermodynamic parameters of the interaction between pulp and ink, an amount of $5.3 \pm 0.2 \mathrm{mg}$ of each ink were manually added to each pulp sample. The samples were transferred to a stainless steel crucibles that it was sealed at 2-tons pressure for 1 minute. The DSC curves were obtained in a Differential Scanning Calorimeter SHIMADZU DSC-50, under nitrogen atmosphere at a constant flow rate of $50 \mathrm{ml} / \mathrm{min}$. The variation of the temperature from $25{ }^{\circ} \mathrm{C}$ up to $500{ }^{\circ} \mathrm{C}$ was performed, by adopting three heating rates of 10 , 15 , and $20^{\circ} \mathrm{C} / \mathrm{min}$ for the inks as well as 15,20 and $25{ }^{\circ} \mathrm{C} / \mathrm{min}$ either for pulps and the interaction between pulps and inks. The kinetic parameters (activation energy and reaction order) were calculated, by using Ozawa's kinetic model available in the program contained in the proper device. For obtaining the enthalpy of the endothermic and exothermic peaks, the heating rate of $15{ }^{\circ} \mathrm{C} / \mathrm{min}$ was used for the inks, pulps and the interaction between pulps and inks. The equipment was previously calibrated for temperature using a standard melting point of indium $\left(156.4{ }^{\circ} \mathrm{C}\right), 99.99 \%$ pure, and the energy calibration was done by using of the enthalpy of melting point $\left(\Delta \mathrm{H}=28,5 \mathrm{~J} \mathrm{~g}^{-1}\right)$ of this same metal. The TGA curves were obtained through the device SHIMADZU model TGA-50, under nitrogen atmosphere at a constant flow rate of $30 \mathrm{ml} / \mathrm{min}$ A sample of $6 \pm 2 \mathrm{mg}$ inks with low, medium and high tack, as well as $4 \pm 2 \mathrm{mg}$ of the pulps with low, medium, and high fiber/vessel rate were taken. The scanning was performed at heating rate of 15 ${ }^{\circ} \mathrm{C} / \mathrm{min}$ at the temperature range from $25^{\circ} \mathrm{C}$ to 500 ${ }^{\circ} \mathrm{C}$.

\section{Analyses by infrared spectroscopy (FT-IR)}

The FT-IR spectra were obtained in a spectrophotometer Perkin Elmer FT-IR 1000 by the diffuse reflectance method for investigating a representative sample of the offset inks. The offset ink samples were placed in a crucible, sent to a muffle furnace in at heating rate of $15{ }^{\circ} \mathrm{C} / \mathrm{min}$ at the temperature range from 25 to $500{ }^{\circ} \mathrm{C}$. Then, at 200, 400 and $500{ }^{\circ} \mathrm{C}$ the muffle furnace was opened and samples were taken.

The FT-IR spectrum of the inks at room temperature, 200, 400 and $500{ }^{\circ} \mathrm{C}$ were measured by preparing a thin ink layer under a cesium Iodide cell (CsI). All spectra were measured at 4000-500 $\mathrm{cm}^{-1}$ range, with $4 \mathrm{~cm}^{-1}$ resolution. 


\section{RESULTS AND DISCUSSION}

\section{The Differential Scanning Calorimetry analysis (DSC)}

Results of the offset ink samples

The thermograms obtained from DSC of the offset ink samples at the heating rate of $15{ }^{\circ} \mathrm{C} / \mathrm{min}$, from 25 to $500{ }^{\circ} \mathrm{C}$ are presented in Figure 1. The peak areas under the obtained curves are the enthalpy $\left(\right.$ cal. $\left.\mathrm{g}^{-1}\right)$ involved into thermodynamic processes that occur at each temperature range. The thermograms of the ink samples showed an endothermic phenomenon (ascendant peak) with the maximum peak temperature ranging from 108 to $116{ }^{\circ} \mathrm{C}$, following an exothermic phenomenon (descending peak) from 425 to $432{ }^{\circ} \mathrm{C}$.

To assign a molecular interpretation to each peak of DSC, it was necessary to accomplish the infrared spectrum analyses of a sample that would be representative for offset ink and its respective pigment isolated at room temperatures, 200, 400 and $500{ }^{\circ} \mathrm{C}$. Figure 2 shows a typical spectrum of the ink at different temperatures. The ink spectrum at room temperature (Fig. 2) showed the presence of bands corresponding to the oils that constituted one of their main components. This spectrum presented the same characteristic bands found by Blayo et al. (2001), who studied the oils from linseed, soybean, and rape.

Figure 2 showed that the offset blue ink probably contained the copper pigments so-called phthalocyanine with typical absorption bands in the infrared at 2936, 2870, 1607, 1505, 1460, 1419, 1375, 1334, 1288, 1166, 1120, 1091, 998, 900, 786, 778, 726, 571 and $506 \mathrm{~cm}^{-1}$ (Havlínová et al., 2002; Newman, 1979). Newman (1979) reported that the phthalocyanines showed very distinct spectrum (particularly near $1700 \mathrm{~cm}^{-1}$ ) in the medium infrared region, as containing well defined narrow bands due to the stretching system of the aromatic ring carbon-carbon bonds, as well as hydrogen-carbon bonds of the rings at the plane and outside the plane.

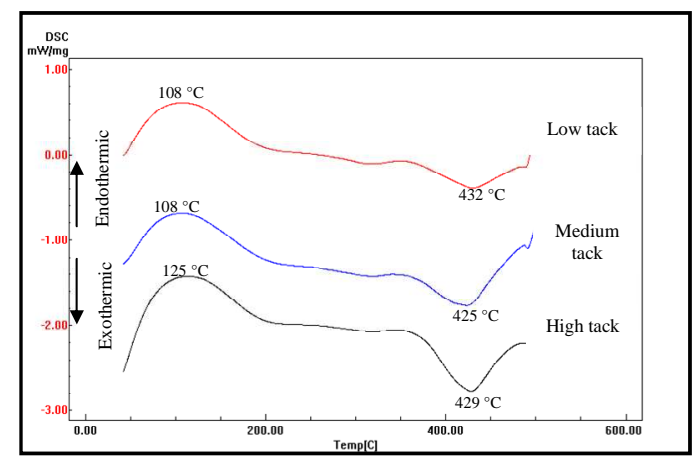

Figure 1 - DSC curves of the offset inks.

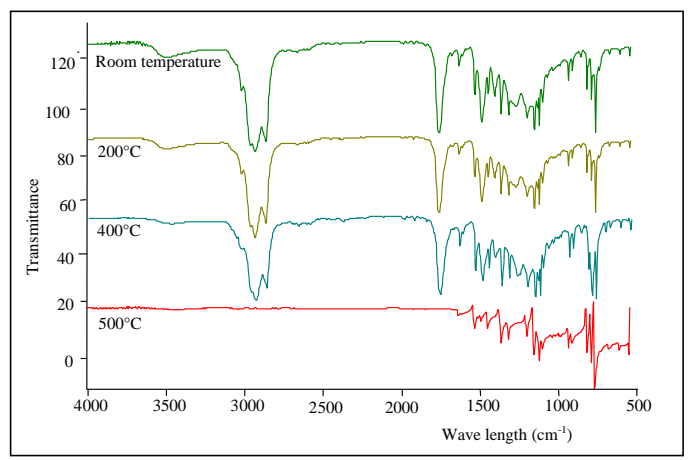

Figure 2 - Spectra obtained by infrared representing the offset inks at room temperature, $200{ }^{\circ} \mathrm{C}$, $400{ }^{\circ} \mathrm{C}$ and $500{ }^{\circ} \mathrm{C}$. 
The infrared spectra of the offset ink showed that no alteration occurred at the temperature range corresponding to the interval from 25 to $200{ }^{\circ} \mathrm{C}$, relative to the structural relationship of its components, indicating no chemical reactions to occur there. Thus, it could be concluded that the endothermic peak observed in the DSC analyses of the inks was due to evaporation of the solvent. The enthalpy values found in the endothermic peaks for both low-tack and medium-tack inks were $53.05 \pm 2.0$ cal.g $^{-1}$, respectively, therefore indicating a similar solvent content in both inks. On the contrary, the high-tack ink that probably contained a higher solvent content, showed a higher enthalpy value $\left(88.86 \pm 2.0 \mathrm{cal}^{\mathrm{g}} \mathrm{g}^{-1}\right)$.
As observed in the infrared spectroscopy analyses (Fig. 2), from $400{ }^{\circ} \mathrm{C}$ some modifications began in the profile of the ink spectrum, whereas at $500{ }^{\circ} \mathrm{C}$, a great degradation of some parts of the ink components occurred due to the disappearance of the bands corresponding to the oils and resins. Therefore, it could be inferred that the exothermic peak observed in the ink DSC analyses (Fig. 1) was due to the total degradation of their component parts, such as the oils and resins, and partially of the pigment. For the values of the exothermic peak enthalpy, as there occurred an increased ink tack (Table 2), the enthalpy values also increased, therefore, suggesting a gradual increase in the content of the solid components such as resins and pigments.

Table 2 - DSC parameters of the samples for the endothermic peak

\begin{tabular}{lcccc}
\hline Sample & $\mathbf{T}_{\text {peak }}\left({ }^{\circ} \mathbf{C}\right)$ & $\mathbf{\Delta} \mathbf{H}\left(\mathbf{c a l . g} \mathbf{g}^{-\mathbf{1}}\right)$ & $\mathbf{E}_{\mathbf{a}}\left(\mathbf{k J J . m o l}^{-\mathbf{1}}\right)$ & $\mathbf{N}$ \\
\hline LT & 108 & 53.05 & 24.06 & 2.1 \\
MT & 108 & 51.76 & 31.32 & 2.5 \\
HT & 116 & 88.86 & 25.75 & 1.5 \\
LR & 122 & 122.34 & 20.38 & 1.8 \\
MR & 124 & 92.05 & 28.38 & 2.8 \\
HR & 133 & 65.09 & 19.10 & 1.0 \\
LR LT & 121 & 39.86 & 20.66 & 1.5 \\
LR MT & 126 & 52.20 & 16.91 & 2.1 \\
LR HT & 133 & 52.58 & 24.22 & 1.1 \\
MR LT & 127 & 25.03 & 21.26 & 1.4 \\
MR MT & 132 & 46.64 & 26.12 & 1.6 \\
MR HT & 134 & 28.73 & 26.63 & 1.5 \\
HR LT & 125 & 39.61 & 24.24 & 1.4 \\
HR MT & 132 & 39.28 & 17.95 & 1.5 \\
HR HT & 128 & 22.48 & 24.56 & 1.7 \\
\hline
\end{tabular}

$\mathrm{T}=$ peak temperature; $\Delta \mathrm{H}=$ enthalpy; Ea = activation energy; $\mathrm{N}=$ reaction order.

Where: $\mathrm{LT}=$ low tack ink; $\mathrm{MT}=$ medium tack ink; $\mathrm{HT}=$ high tack ink; $\mathrm{LR}=$ low fiber/vessel rate pulp; $\mathrm{MR}=$ average fiber/vessel rate pulp; and HR = high fiber/vessel rate pulp.

\section{Results of the pulp samples}

Figure 3 shows the thermograms obtained from DSC of the pulp samples at the heating rate of 15 ${ }^{\circ} \mathrm{C} / \mathrm{min}$, from 25 up to $500{ }^{\circ} \mathrm{C}$. The presence of two different phenomena for those three pulp samples under study was observed. The endothermic phenomenon occurred at the maximum temperature range from 122 to $133{ }^{\circ} \mathrm{C}$, and the exothermic from 314 to $340{ }^{\circ} \mathrm{C}$. Liu et al. (2004) evaluated the pyrolysis of wood derivatives by thermogravimetry associated with mass spectrometry. The first detected peak appeared at the temperature range from 80 to $220^{\circ} \mathrm{C}$, with maximum peak at $125{ }^{\circ} \mathrm{C}$ that was due to the physical desorption of the water. It was observed that between 300 and $400{ }^{\circ} \mathrm{C}$, the depolymerization of glucose units occured with the formation of levoglucosans and decomposition of the remaining water into carbon monoxide, carbon dioxide and char. 


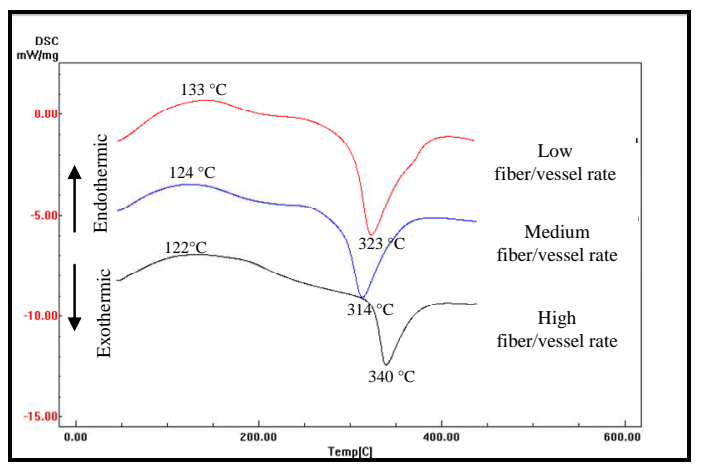

Figure 3 - DSC curves of the pulp samples.

An endothermic phenomenon was observed in the pulp samples at the temperature range of 25 to 200 ${ }^{\circ} \mathrm{C}$. The enthalpy values for the endothermic phenomenon of the samples with low, medium, and high fiber/vessel rate were: $122.34,92.05$ and 65.09 cal.g $^{-1}$, respectively. It is known that this endothermic phenomenon is due to water desorption (Liu et al., 2004). Despite all samples tested with the same moisture content $(6 \%)$ a higher energy was needed for desorption of water molecules on the pulp with low fiber/vessel rate. In order to explain this difference in the consumption of energy, the pulp samples under the form of handsheets were submitted to the airresistance test, as described in the item 'materials and methods'. This test constitutes a measure related to the porosity of the paper. The following values were found for the pulp with low and high fiber/vessel rate: $4.05 \mathrm{~s}$ and $0.97 \mathrm{~s} / 100 \mathrm{~cm}^{3}$ air, respectively. Based on this result, one could infer that as higher was the resistance to the passage of air, the higher would be the necessary energy to occur the evaporation of the water molecules kept in the pulp structure during the heating process, when analyzing DSC. This behavior is probably explained due to the highest contents of fines found in the pulp with low fiber/vessel rate, which supply a higher superficial area for the adsorption of the water molecules.

In addition, an exothermic phenomenon was found in pulp samples which was due to depolymerization of glucose units (Liu et al., 2004) The enthalpy values found in the exothermic phenomenon for the samples of low, medium, and high fiber/vessel rate were: $-125.2 ;-118$; and 108.6 cal. $^{-1}$, respectively. Although the pulp samples with low and high rate have basically presented the same polymerization degree, which was shown by the proximity of the values for their viscosities (15.2 and $16.0 \mathrm{cP}$, respectively), it was observed that the energy released during the depolymerization of the cellulose chains were different among the pulps.

The results from the technological characterization of the pulps showed that the samples with high fiber/vessel rate presented higher values for the average length of the fibrous material $(0.84 \mathrm{~mm})$, coarseness $(4.8 \mathrm{mg} / 100 \mathrm{~m})$ and fine contents (4.98\%), when compared to the pulp with low fiber/vessel rate that presented average length of the fibrous material $(0.49 \mathrm{~mm})$, coarseness $(2.2$ $\mathrm{mg} / 100 \mathrm{~m})$ and fine contents $(13.44 \%)$. This caused the formation of more porous handsheets and the pulp with high fiber/vessel rate probably leading to a higher accessibility for breaking of the glycosidic bonds of the chains, therefore generating a lower release of energy (exothermal reaction) during the chemical linkage breaking process.

\section{Results from the pulp and ink interaction}

According to Hartus (1999), the interactions between inks and fibers in the DSC analysis can be detected by changes in the consumption of energy and/or in peak temperature corresponding to a determined thermal transition. One could observe in the interaction between pulps and inks (Fig. 4) that both the endothermic and exothermic phenomena were presented (Fig. 3). For the endothermic phenomenon, the maximum temperature range from 120 to $134{ }^{\circ} \mathrm{C}$ was observed.

Table 2 shows the thermodynamic parameters for the samples of the inks, pulp and interaction between ink and pulp. It was be observed that the values for enthalpy in the interactions between 
pulp and ink for all samples were always lower, compared with the values found in the pulp samples.

Aiming at the investigation of the causes of the decreased enthalpy, the thermogravimetric analysis was carried out in order to evaluate the amount of matter that participates into each endothermic and exothermic transition.

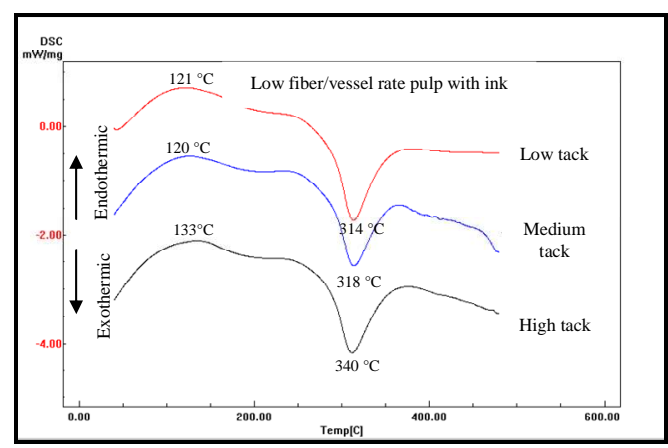

a

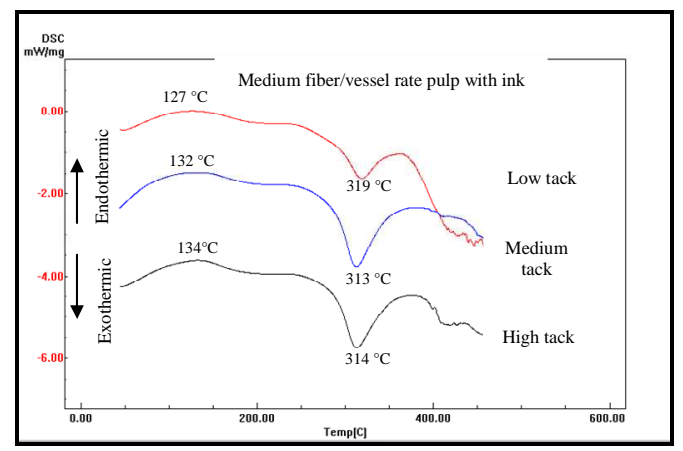

b

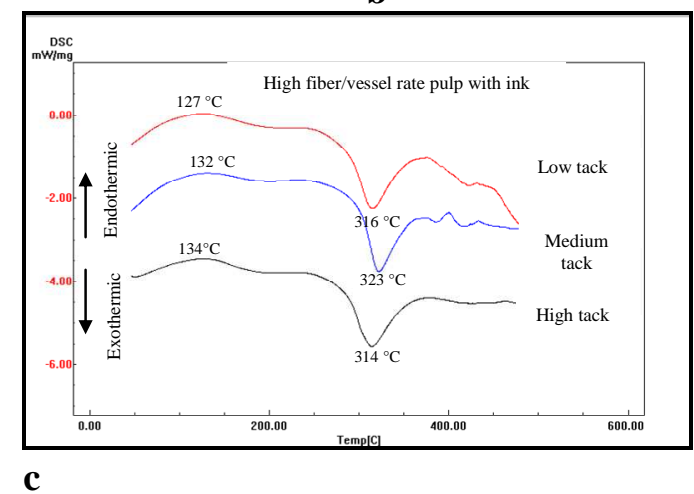

Figure 4 - Thermograms of the interaction between pulp and offset ink obtained from DSC. a) Low fiber/vessel rate pulp and inks; b) Medium fiber/vessel rate pulp and inks; and c) High fiber/vessel rate pulp and inks.

\section{Thermogravimetry analyses (TGA)}

According to Hartus (1999), the interactions among ink and the fiber components in TGA will occur with changes in weight loss at determined temperature range, changes in the weight loss rate taxes, or changes in temperature corresponding to the highest rate of mass loss.

In the thermograms obtained from the interaction between pulp samples and inks, an initial weight loss was observed at the range from 25 to $200{ }^{\circ} \mathrm{C}$, which corresponded to the sum of the water evaporation molecules of the pulp samples and the ink solvent molecules, as well as a higher weight loss as those found in the analyses accomplished in DSC at the range from 300 to $500{ }^{\circ} \mathrm{C}$, which corresponded to degradation of either the cellulose chains and ink components.

The matter amount foreseen for the endothermic transition in interaction between pulp and ink was given by the sum of the weight loss due to evaporation of the water molecules in the pulp plus the weight loss of the ink solvent molecules. These foreseen values and those experimentally obtained in TGA are shown in Figure 5. 

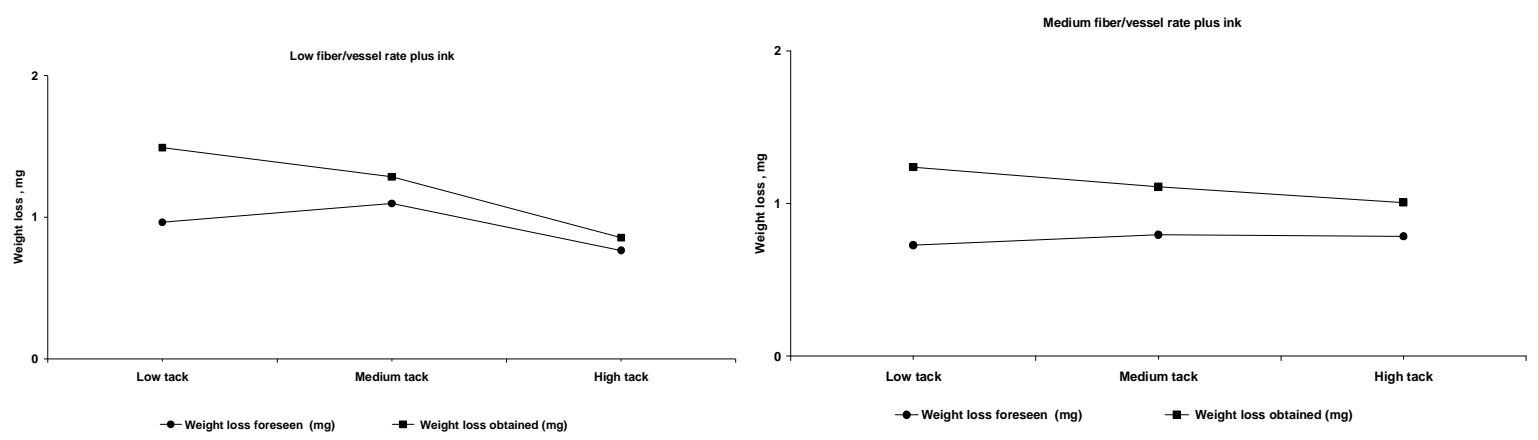

a

b

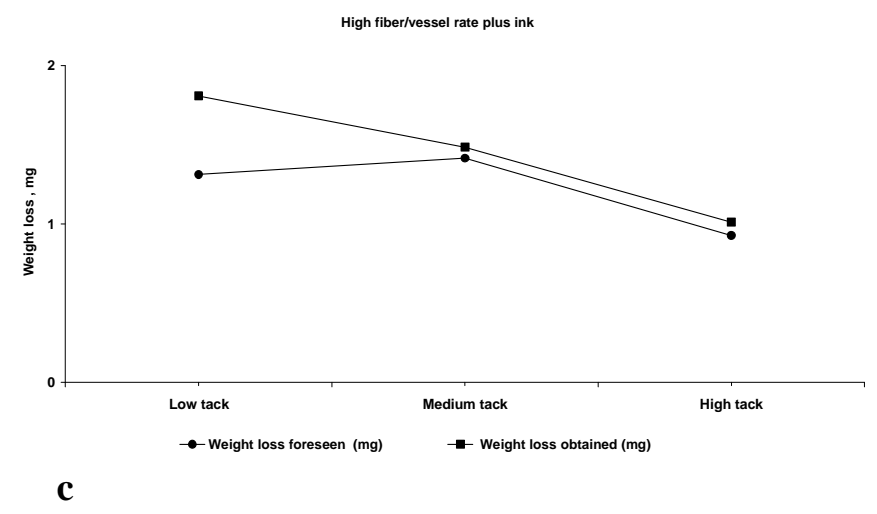

Figure 5 - Results of the weight loss obtained from TGA of the interaction between pulp and offset ink. a) Low fiber/vessel rate pulp and inks; b) Medium fiber/vessel rate pulp and inks; and c) High fiber/vessel rate pulp and inks.

It was observed that the amount of both water and solvent molecules evaporated in the interaction were superior to the foreseen amount, for all samples under study. Based on these results, one could infer that the decreased enthalpy values of the endothermic peak in the DSC analysis were not due to a decreased matter in the pulp and/or ink samples. Thus, this decreased energy could only be attributed to the released energy (exothermal process) during absorption of the ink pigment to the surface of the pulp.

\section{Interaction between fibers and vessel elements with offset printing inks}

The enthalpy values $\left(\mathrm{cal}_{\mathrm{g}} \mathrm{g}^{-1}\right)$ foreseen for the endothermic phenomenon in the interaction of pulps and inks corresponded to the sum of water molecule evaporations in the pulp substratum plus the ink solvent molecules. The real values obtained by Differential Scanning Calorimetry (DSC) for this phenomenon and the difference found between the foreseen enthalpy and the real enthalpy for all samples are represented in Figure 6. The enthalpy values obtained by adhesion of the ink pigments on the pulps ranged from 58.1 to 121.0 cal.g ${ }^{-1}$ (Table 3). According to the enthalpy values, it could be inferred that this adhesion did not occur by covalent bonds, where the energy from 4000 to $5000 \mathrm{cal}^{-\mathrm{g}^{-1}}$ was needed, but it probably occurred through physical adsorption (hydrogen bonds, van der Waals forces, electrostatic attraction) and penetration of the ink pigment molecules through the capillaries of the fibers.

Johansson et al. (1989) studied the way the alkyd resins were kept on the surface of cellulose. They concluded that chemical interactions could occur between the carboxylic acid groups in the alkyd resins and the reactive sites of the cellulose surface. The resin adhered to the surface of the fibers by an exothermal phenomenon $(\Delta \mathrm{H}$ : -9.4 $\mathrm{kJ} . \mathrm{mol}^{-1}$ ) determined by intermolecular interactions of the van der Walls forces, but not by chemical bonds. 
In Table 3, one could observe that as smaller the fiber/vessel rate pulp the higher would be the content of vessel elements in the fraction, as well as there would be a tendency for increasing the energy released for adhesion of the pigment into substratum for all ink samples. Thus, those enthalpy differences between the fractions with higher contents of vessel elements and higher fiber contents could be due to both chemical and physical nature of the samples.

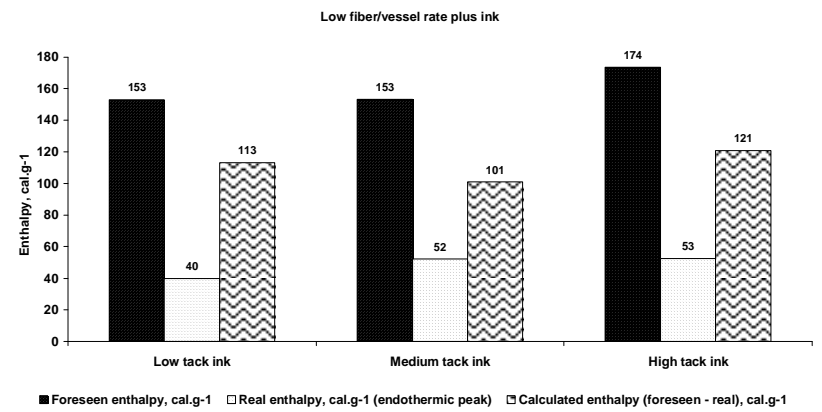

a

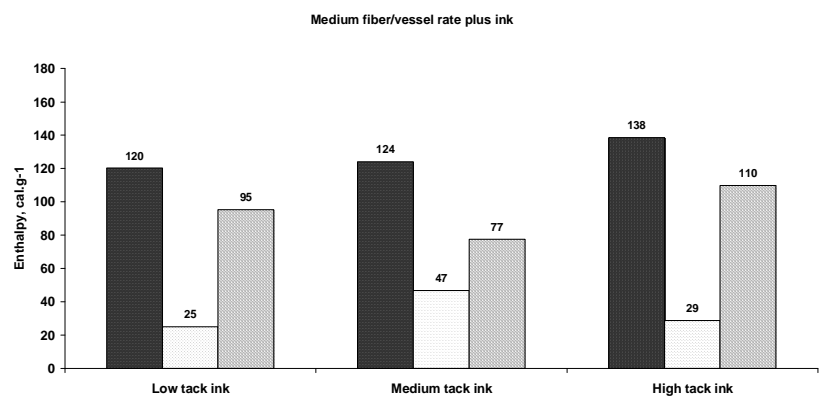

b

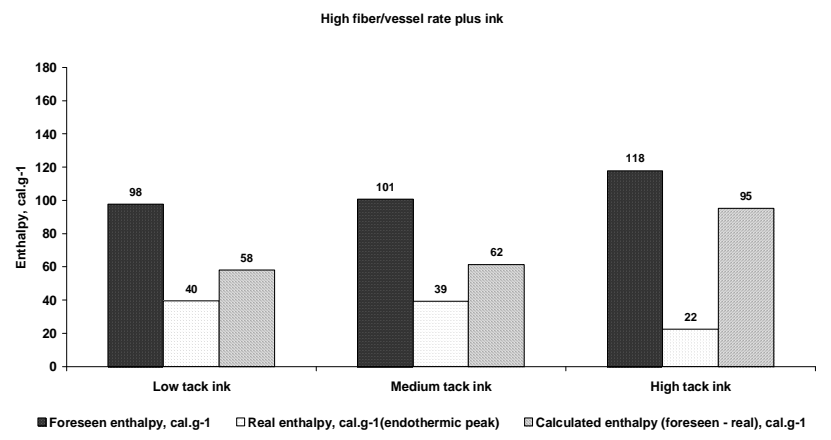

Figure 6 - Enthalpy values obtained from DSC of the interaction between the pulp and ink samples. a) Low fiber/vessel rate pulp and the low, medium and high tack inks; b) Medium fiber/vessel rate pulp and the low, medium and high tack inks; and c) High fiber/vessel rate pulp and the low, medium and high tack ink 
Table 3 - Enthalpy values obtained from DSC in the interaction of the ink samples with the samples of low, medium and high fiber/vessel rate

\begin{tabular}{cccc}
\hline & \multicolumn{3}{c}{ Enthalpy, cal.g $^{-1}$} \\
\cline { 2 - 4 } Fiber/vessel rate & Low tack ink & Medium tack ink & High tack ink \\
\hline Low & 113.1 & 101.7 & 121.0 \\
Medium & 95.2 & 77.4 & 109.7 \\
High & 58.1 & 61.5 & 95.2 \\
\hline
\end{tabular}

The carbohydrate analyses in the low fiber/vessel rate sample showed higher content of xylan $(14.4 \%)$ and lower glucans $(77.6 \%)$, whereas in the sample with high fiber/vessel rate showed lower xylan contents $(13.8 \%)$ and higher glucans $(81.4 \%)$. It is well-known that xylans are the main hemicelluloses in hardwood (Medeiros, 2007). For each 10 xylose units, these hardwoods presented 7 units of acetyl groups as well as from 1 to 2 units of 4-0-metylglucuronic acid (Sjöström, 1993). Cellulose that is the main carbohydrate found in the wood, presents the alcoholic and hemiacetalic groups and carboxylic groups as functional ones.

It is known that reactivity of the hemicelluloses is higher than the cellulose due to both chemical and physical differences of these components. Concerning the chemical characteristic, the hemicelluloses present a higher number of functional groups, such as acetyl, carboxyl, and methoxyl, as well as their monomers are less stable for presenting five-carbon rings, besides having a lower molecular weight, which leads to a lower stability of the molecule. Concerning the physical characteristic, they are shown under ramified chains and consequently amorphous, therefore leading to a higher accessibility within their chain.

Thus, it could be inferred that the highest content of hemicelluloses in the sample enriched with vessel elements might have increased the reactivity of the substratum, since they presented higher number of possible reaction sites, besides leading a higher accessibility to these reactive groups due to the presence of the ramified chains. On the contrary, the fiber-enriched sample (higher fiber/vessel rate) presented higher glucan contents that showed more crystalline chains as well as a lower amount of reactive sites for adhesion of the ink pigment. The vessel elements also presented a highly different anatomical characteristic compared to the fibers since, their diameters were much larger than those fibers (Burger and Richter, 1991) The most common shape to the eucalyptus wood is popularly called as barrel wooden shape that is shorter and broader cells

The studies concerning the separation of the nonfibrous components in oak wood accomplished by Klungness and Sanyer (1981) showed that the specific surface of the vessel elements was almost $50 \%$ higher than that of the fibers, and the specific volume twice as higher. Thus, the low fiber/vessel rate fraction that was that most enriched with vessel elements, probably released a higher energy amount in the adhesion of the pigment on the pulp because it has a broader specific surface compared to the fibers. Thus, besides the vessel elements to possess a chemical structure with higher amount of reactive sites, the vessel elements should also have a higher specific area for a possible interaction.

The energy liberated from the adhesion of the pigment into substratum (pulp) was higher for all pulps samples under study, when using the high tack ink (Table 3). This phenomenon could be explained by the amount of the pigment used in formulating this ink type. With the results for loss of the ink weight obtained by TGA, a higher mass was observed in the exothermic peak, which corresponded to degradation of both resins and pigments for the high tack ink. This occurrence led to the conviction that a higher pigment quantity was used in the formulation of the high tack ink, therefore, increasing the number of particles by area that adhered to the substratum, thus releasing higher energy.

\section{CONCLUSION}

Molecular interactions among the components of pulp and offset printing inks were determined by thermal analyzes of DSC and TGA. These analyses showed an evaporation of the solvent to occur at 25 to $200^{\circ} \mathrm{C}$, whereas the degradation of some ink component parts began above $300^{\circ} \mathrm{C}$. Thus, the settling of the ink would be easier with the increased temperature since it did not surpass 
$300^{\circ} \mathrm{C}$. However, thermogravimetric analyzes of the pulp showed its thermal stability to occur only until $200^{\circ} \mathrm{C}$, which led to suggest this temperature as the maximum assurance level for the printing with those offset inks.

The adsorption of the pigment to the pulp occured exothermically at enthalpy values related to physical interactions, such as hydrogen bonds, van der Waals forces and electrostatic attractions, in which higher interaction was also observed among the ink pigments with vessel elements

\section{RESUMO}

O conhecimento técnico-científico das interações que ocorrem no processo de impressão offset é escasso, embora várias observações mostrem sua importância. O objetivo deste trabalho foi estudar por análises térmicas e espectroscópicas, na região 1do infravermelho, o tipo de interação dos componentes anatômicos da polpa branqueada kraft de eucalipto com tintas de impressão offset. Foi utilizado um classificador de fibras BauerMcNett com o intuito de se obter os componentes anatômicos da polpa separadamente. As determinações da entalpia dos processos que ocorrem com as amostras de tintas, polpa e também a entalpia de interação destes componentes foram obtidas por Calorimetria Diferencial de Varredura. Na interação entre polpa e tinta offset, a redução dos valores de entalpia do pico endotérmico foi interpretada como sendo devida à liberação de energia para a adesão do pigmento da tinta ao substrato. Os baixos valores de entalpia (58 a $121 \mathrm{cal}^{-\mathrm{g}^{-1}}$ ) indicam que o assentamento da tinta ocorre por meio de interações físicas A fração de polpa enriquecida com elementos de vasos acarreta uma maior liberação de energia, durante a aderência do pigmento na polpa.

\section{REFERENCES}

Blayo, A.; Gandini, A.; Le Nest, J. F. (2001), Chemical and rheological characterization of some vegetable oils derivatives commonly used in printing inks. Industrial Crops and Products, 14, 155-167.

Burger, L. M.; Richter, H. G. (1991) Anatomia da madeira. São Paulo. Editora Nobel. 154p.
Colley, J.; Crossi, P.; Tabart, J. (1986) Overcoming the vessel picking tendency of coated papers. Appita, Carlton, 39, n. 1, p. 26-30.

Devallencourt, C.; Saiter, J. M.; Capitaine, D. (1996), Characterization of reclycled celluloses: thermogravimetry/Fourier transform infra-red coupling and thermogravimetry investigations. Polymer Degradation and Stability, 52, 327-334.

Hartus, T. (1999), Thermal analysis of ink-substrate interactions and drying in ink jet printing. Graphic Arts in Finland, Finland, 28, n. 1, 3 -10.

Hartus, T.; Oittinen, P. (1996), Characterization of the drying properties of heatset inks by thermal methods. Graphic Arts in Finland, Finland, 25, n. 1, 9-15.

Havlínová, B.; Babiaková, D.; Brezová, V.; Durovic, M.; Novotná, M.; Belányi, F. (2002), The stability of offset inks on paper upon ageing. Dyes and Pigments, 54, 173-188.

Heintze, H. U.; Shallhorn, P. M. Hardwood vessel picking and the manufacturing process. (1995) Pulp and Paper Canada, Ontario, 96 (11), p. T365-T367.

Johansson, K.; Ström, G.; Stenius, P. (1989), Sorption of alkyd resins on cellulose. Paper presented at 10 ${ }^{\text {th }}$ Cellulose and Wood-Chemistry and Technology, Wiley, New York.

Klungness, J. H.; Sanyer, N. (1981), Hardwood pulp utilization. Separation of nonfibrous oak components. Tappi Journal, Atlanta, 64 (2) 109-113.

Liu, Q.; Lv, C.; Yang, Y.; He, F.; Ling, L. (2004), Study on the pyrolysis of wood-derived rayon fiber by thermogravimetry-mass spectrometry. Journal of Molecular Structure, 733, 193-202.

Medeiros, Roseli Garcia et al. Application of xylanases from Amazon Forest fungal species in bleaching of eucalyptus kraft pulps. Braz. arch. biol. technol., Mar 2007, 50 (2), p.231-238.

Newman, R. (1979), Some applications of infrared spectroscopy in the examination of painting materials. Journal of the American Institute for Conservation, 19 (1), 42-62.

Ohsawa, J. (1988), Vessel picking in printing papers. Paper presented at Tropical Wood Pulp Symposium, Singapore.

Ramos, L. P. et al. Comparison of the susceptibility of two hardwood species, Mimosa scabrella Benth and Eucalyptus viminalis labill, to steam explosion and enzymatic hydrolysis.Braz. arch. biol. technol., 2000, vol.43 (.2), p.195-206.

Sjöström, E. (1993) Wood Chemistry. Fundamentals and Applications, 2nd edition, Academic Press, San Diego, CA, USA, 293 p
Received: August 18, 2006; Revised: December 12, 2007; Accepted: January 07, 2009. 